\title{
Contributions of ergonomics to the construction of bus drivers health and excellence in public transport and at work
}

\author{
Claudio Brunoro*, Laerte Idal Sznelwar, Ivan Bolis and Julia Abrahão. \\ Production Engineering department, Universidade de São Paulo, Av. Prof. Almeida Prado, Travessa 2, $N^{o} 128$, \\ São Paulo, Brazil.
}

\begin{abstract}
This article is the product of research that analyzed the work of bus drivers of a public transportation company that is considered a benchmark reference in its field of operations, in which it strives to achieve operating excellence. Within this context, the authors sought to understand how such a company has managed to maintain a policy that is capable of reconciling quality public transport while also providing working conditions compatible with the professional development, comfort and health of its workers. Ergonomic work analysis and activity analysis were the guiding elements used in this study. Initial analyses indicate that the activity of drivers includes serving a population and providing mobility for it, which depends on driving the vehicle itself and on relationships with colleagues, users, pedestrians, drivers and others.
\end{abstract}

Keywords: activity theory; state-owned company; organizational design.

\section{Introduction}

Excellence in public transport poses challenges for everyone, including system and company managers and all the workers involved in direct and support operations, including the drivers, whose work is the focus of this research. Company governance in itself is limited by a number of contractual and reality aspects and includes relations with users and their needs, city characteristics and conditions, and the incorporation of different types of transportation technology, including the vehicles. Obviously, the cost/revenue relationship mediates the entire process and determines the margin of maneuver of the different players in the system.

The pursuit of excellence and its upkeep is the result of organizational congruence that affects all the company levels and, more directly, the operation and maintenance issues. The work of those who are in direct contact with users, the driver / fare collector duo (crew), forms part of this perspective. To achieve organizational congruence it is essential to establish the conditions for conducting excellent work, since it is the work of this pair of workers, and especially of the driver, which in the final instance guarantees excellent transportation. In this case, excellent transportation does not mean taking something from one place to another, but guaranteeing excellence in the movement of people, who have different conditions, needs and concerns.

The purpose of this study is to understand how a Brazilian company can maintain a policy that reconciles quality public transport with working conditions compatible with the professional development, comfort and health of its workers.

\subsection{The challenges faced by the company in its pursuit of excellence}

Excellence for the operation of this company means the quality of the service provided, the financial aspects, and the health of its workers (drivers, conductors and internal company support area work-

*Corresponding author. E-mail: cbrunoro@uol.com.br. 
ers); assessment of this is supported by different indicators. The classic indicators of the financial aspects are profitability and investment capacity. Even though it is a company (as opposed to a non-profit organization), its role is to structure the operating system and distribute revenue to other companies in the system, based on the higher IPK [index of passengers per kilometer traveled] with which it operates. However, it is also to generate surplus funds for investing in the system itself, leading to improvement of the service provision quality indicators.

The indicators that the company employs are those that are common to operators of urban passenger public transport systems. The company's system indicators, however, appear to lack "passengers carried per square meter (average)." Though a key passenger comfort indicator, this tends to be ignored in the system, as better results on this count normally imply an IPK reduction (unless passenger turnover on the line is high enough to offset this impact).

Fleet quality and standardization, making maintenance easier and providing quality elements for passengers and drivers (rear-mounted engine, low floor, air-conditioning, servo-assisted brakes, automatic transmission), have a strong impact on the three sets of elements of which quality is comprised - quality for the user, for the shareholder (and taxpayer) and for the worker.

A quality increase for the user or the driver (automatic transmission, for example) can mean a weaker financial performance, this being the critical point of the issue of determining the company's strategy: the ideal, temporally planned combination of indicators for company managers.

\section{Results}

\subsection{Driver activity: managing micro aspects for macro excellence}

The work of bus drivers is governed by conditions that are both internal and external to the organization. It is possible, therefore, to work with two mediating dimensions of excellence: the first concerns conditions external to the company and the second, the standards and rules that organize the company internally.

Among the external factors that influence putting excellence into operating practice, there are different elements that act in particular ways and over which the company has little power:
- Fleet quality - making decisions that are conditional upon external demands about when and how to renew the fleet;

- Strategic planning of the system - route creation or changes, trip detours, the allocation of routes to the companies of other consortia, and the dimensions of the routes (frequency, type of vehicle);

- Revenues generated by the company's transportation system - the differentiated cost in the division of revenue;

- Traffic - a mediator of punctuality that influences user assessment;

- Quality of the roads - being highly uneven, they affect speed, maintenance and, consequently, journey punctuality;

- Unexpected incidents - hold-ups, accidents and other factors; and

- User assessment - carried out taking punctuality into account, the critical spirit of the population and the interpersonal relations with drivers.

As for the internal determinants, they arise from overlapping decisions and they are by nature organizational and political, such as changes in company management, organizational determinants, the new vehicle acquisition process, operational capacity, time management on the routes to prevent occupational fatigue, and regulation strategies for maintaining operational quality.

Based on activity analysis approach [7], and within the above context, the main variables that determine and condition the drivers' working conditions can be summarized as follows:

- The acting and interactions in the public space of the city;

- The quality of the materials and equipment available to the driver; the time management;

- The quest for and management of information;

- The organization of routes and times; and

- The relations with users.

This interdependence between such distinct factors means that working with the prospect of achieving and maintaining high levels of excellence goes beyond planning the fleet size appropriately and acquiring vehicles. Excellence is achieved through service that also demands social inter-relations, with many, if not the vast majority of them, resulting from the action of the driver. Thus, the driver's work can also be seen as that of a regulatory agent of the system, since this person must manage the times imposed by the system and the most varied ranges of events that affect the reality. 
We must mention that if on the one hand the driver is a regulatory agent, on the other this driver experiences constant conflict and pressure from the organization and from the management of the system for maintaining the requisite service level, this being expressed in indicators often analyzed without a more systemic view, one that encompasses the complexity of reality. Additionally, when it comes to users, there is a series of requirements resulting from their expectations about the quality of the service. It is a major challenge for company management and system managers to take all of this into account.

Driver activity is permeated with random events and contretemps. In some situations, if not most, the driver's action consists of anticipating incidents and accidents. The driver needs to act preventively [12]. It is in this management of circumstances that his or her different competences become apparent. One such competence is the capacity to manage the different events that faced during the course of the workday, the aim being to ensure efficiency and effectiveness in the transportation of people. However, it is difficult to measure and to put a value on these competences, since when the driver is successful his or her action goes unseen and is not computed [6]. This is because classic management indicators do not take into consideration driver dedication to dealing with reality; there is little or no room for the reality of this work to become evident.

Another point that should be mentioned is that, unfortunately, the work of the driver tends to turn into the system's adjustment variable, particularly in connection with managing time [1]. The expression of this is found in the variation in resting breaks, particularly at peak times, when they are substantially reduced. In itself this is not a problem, but may become one if, as previously mentioned, the working reality of drivers and the possibility of conditions arising that are conducive to the development of chronic fatigue and different types of pathologies are not considered [8].

Facing up to this variability, which is repeated over days and years, is one of the challenges that drivers face in their pursuit of service excellence and to ensure their own image and that of the company. There is always some managing required regarding what should be favored in strategic decisions, with work quality being one of the core aspects. The quality of this management depends on organizational congruence, which should be capable of taking into account different aspects, such as the work performed by its workers, the inclusion of citizenship in connection with the quality of mobility, and technological development.

\subsection{Work and health}

Based on Ergonomic Work Analysis [10], the analysis of the data of this study enabled stating the importance of considering a range of variables and their inter-relationships in order to understand the challenges faced in ensuring the production of transportation services and work regarded as excellent. This discussion focuses on understanding the context that regulates the work of bus drivers.

Just as the aforementioned characteristics have a significant influence on modulating the work of drivers, the technological aspects made available to drivers are also of the utmost importance in terms of excellence and the quality of their performance. In the case of vehicles, the quality of the buses influences working conditions significantly. In this particular case, it is considered vehicles that are in fact conceived as buses and that incorporate technology that improves the comfort of passengers and of drivers.

The repetitive movements throughout the journey illustrate just how much is required of certain muscles every day. Naturally, over the years, degeneration of this group of muscles is to be expected. Over time, this may be a determinant of the appearance of musculoskeletal problems. One should stress that it is not only movement repetition that can be problematic, but also uncomfortable postures and postural immobility over time $[14,16]$.

Road and traffic conditions, holding a job associated with its physical configuration, attention requirements and maintaining postures over time that force the muscle groups in the dorsal and cervical regions and in the shoulders help explain the leaves of absence indicated by the medical service and concerning musculoskeletal problems. The most frequent reason for taking leave of absence from work regards musculoskeletal disorders (RSI / WMSD). Among these, it is worth highlighting neck pain, lower back pain, spinal degeneration, bursitis, carpal syndrome, problems in the knees due to handling the manual gearshift and obesity $[2,3,11,13]$. In the case of front-engine vehicles, there is also greater exposure to noise, heat and vibration, which may increase the risk of hearing disturbances and hypertension and, as is very prevalent in the category, varicose veins $[4,5]$. 
We identified problems of another nature, which are also worrisome, such as leaves of absence from work resulting from psychological problems, as well as the consequences of work-related accidents.

Concerning impacts linked to the anxietygenerating situations experienced by the drivers, there is no conclusive elements for relating them to health issues, although evidence of musculoskeletal disturbances, such as RSI / WMSD, is common among drivers. There is also evidence that psychological suffering is fairly prevalent in this category. There has been a reported rise in the number of complaints that reaches the worker healthcare services and the social assistance services. Additionally, dealing with robberies (which almost invariably involve a firearm) and with the wide range of forms of aggression and dispute that can occur in contact with other drivers, along with the risk of injuring a passenger, the occupants of automobiles, pedestrians or cyclists, is part of a driver's everyday working life $[9,15]$.

Furthermore, the robberies that happen inside buses, with the driver and the fare collector often being held captive, do not enter the statistics of workrelated accidents. Robberies are currently seen as one of the events responsible for emotionally destabilizing the team that works in the operation. The crew is trained not to react to a hold-up. Working under these conditions and maintaining the requirements of excellence implies hiding fear, submitting to the mishaps of the profession, and being cordial with everyone without knowing whether the next user is going to be an robber or not.

In accident situations when there is a victim, the social service workers are sent to the site. The company maintains two people permanently on-call, even at weekends, to do this. There are few serious accidents, according to the company, thanks to a great deal of prevention. "The organization's strategy is to show that the driver is not alone, that there is a structure that can give him support and that it considers itself co-responsible for the errors". In these circumstances, it is explained to the driver that there are various reasons for an accident, such as the need for maintenance or better training, or management pressure. The purpose of this assistance is to mitigate the stress and strengthen the employee. Everything begins with the principle that nothing is intentional: "an intentional accident is extremely rare, even though it can happen."

Drivers are not penalized financially for accidents involving the vehicle that are under their responsibility and third parties. However, "when a driver 'hits' others more than he should, he probably ends up get- ting dismissed". An incentive policy is currently being studied for "good" drivers, i.e., those who go for the longest time with no accidents and no damage to the vehicle, or those who cause the least amount of damage over a given time span.

The social service is the first 'sympathetic ear', where workers have the freedom to talk about their complaints and personal problems; it is described by the workers as a facilitating sector. Its focus is to support workers regarding issues tied to social relations, particularly to conflicts, fears and anxieties. The biggest complaint concerns interpersonal relationship difficulties (with bosses, colleagues, customers, traffic, etc.). They comment that often the conflict is associated with the allocation of their working hours. "The best work schedules are hotly contested and anyone denied them gets upset because they can find no reason for such a decision."

All workers have a free medical consultation plan as outpatients, while the hospital plan is subsidized by the company and the worker pays a contribution, similar to private health plans. If the worker has no health plan, the social service tries to help and may be able to obtain courtesy treatment, or at least refer the person to SUS [the government-run unified healthcare system].

\section{Analysis}

This study was based on two assumptions: the construction and ongoing pursuit of excellence in service is a constant challenge that depends on factors that are both internal and external to the organization; and the work of the bus driver is not limited to driving a vehicle and cannot be analyzed merely as transportation from one place to another.

Ensuring an organizational alignment that integrates the needs of the population, financial and technical issues and the different types of work undertaken in the company helps to construct health and to prevent occupational illnesses, which are very prevalent in this profession. These are the aspects that comprise excellent service. Continuous monitoring of aspects tied to the comfort and construction of the health of the driver in a broader sense constitutes the framework of excellence.

The excellence attributed to the service supplied by the company is underpinned by the support provided to its employees at different times in their lives. Thus, the data indicate that effort and organizational alignment permeate different structures in the com- 
pany, the aim being to construct and maintain excellence.

\section{Conclusion}

The issue of establishing what quality level is expected of a public transport system is one that must be seen as a decision of a political and strategic nature, involving the different social players who, in one way or another, have an influence on the issue of citizenship and the provision of mobility to the population. Therefore, it extends far beyond controlling journey times; the different users and the differences between users have to be considered, as well as a conceptual expansion of what the mobility service consists of. Providing this service with excellence, therefore, depends on spheres that go beyond the governability of the company, in the strictest sense of the word. The company faces a major challenge: that of making the issues that appear in the day-to-day routine of its operation and system visible to the public spheres of power.

Another question must also be raised: is it possible to operate an excellent service without having an excellent operation? In this case there is a three-way unambiguous relationship between the quality of the service provided, the economic and financial issues and promoting professional development and the health of the workers. If the operation is not excellent, the service will not be excellent, since operating excellence requires excellent work. Furthermore, it must be emphasized that service quality depends on a systemic alignment, covering everything from strategic decisions about management of the transport system to organizational decisions that fall within the scope corporate governance, which regulate the operation itself. Contact with citizens is the final instance in the relationship of the service, whose quality is modulated by how the driver acts.

From this standpoint, in order to provide the conditions needed to ensure excellent service, it is important to maintain and reinforce those company policies that aim to provide drivers and other workers with working, professional and personal support conditions for developing their professional identity and constructing health.

The quality of the fleet and its standardization, in order to facilitate maintenance and to provide quality elements for passengers and drivers (rear-mounted engine, low floor, air-conditioning, servo-assisted brakes, automatic transmission), have a strong impact on the three sets of elements that make up quality for the user, for the shareholder (and taxpayer) and for the worker.

An increase in the investment in quality for users or for drivers (investment in technology, for example) may have a significant financial impact initially. This is a critical element for the issue of determining the company's strategy: to determine what is the ideal combination of indicators, planned in terms of time, in order to manage the company.

\section{References}

[1] Abrahão, J.; Sznelwar, L.I.; Silvino, A.; Sarmet, M. Pinho, D. Introdução à ergonomia da prática à teoria. São Paulo: Blucher, 2009.

[2] Alperovitch-Najenson, D., Katz-Leurer, M., Santo, Y., Golman, D. and $\mathrm{K}$ alichman, L., Upper body quadrant pain in bus drivers. Archives of Environmental and Occupational Health, 65(4), pp. 218-223. 2010.

[3] Anderson, R., The back pain of bus drivers: Prevalence in an urban area of California. Spine, 17(12), pp. 1481-1488. 1992.

[4] Blood, R.P., Ploger, J.D., Yost, M.G., Ching, R.P., Johnson, P.W.,. Whole body vibration exposures in metropolitan bus drivers: A comparison of three seats. Journal of Sound and Vibration, 329(1), pp. 109-120. 2010.

[5] Bovenzi, M. and Zadini, A., Self-reported low back symptoms in urban bus drivers exposed to whole-body vibration. Spine, 17(9), pp. 1048-1059. 1992.

[6] Daniellou, F. A ergonomia em busca de seus princípios: debates epistemológicos. São Paulo, Edgar Blucher, 2004.

[7] Falzon, P. Ergonomia. São Paulo, Edgard Blucher, 2007.

[8] Gilbert-ouimet, M., Brisson, C., Vezina, M., Trudel, L., Benoit, M., Bourbonnais, R., Baril-Gingras, G., Dionne, C.E. Intervention study on psychosocial work factors and mental health and musculoskeletal outcomes. Healthcare Papers, 11 (Spec. Issue), pp. 47-66. 2011.

[9] Gobel, M., Springer, J. and Scherff, J., Stress and strain of short haul bus drivers: Psychophysiology as a design oriented method for analysis. Ergonomics, 41(5), pp. 563-580. 1998.

[10] Guerin, F; et al., Compreender o trabalho para transformá-lo: a prática da ergonomia. São Paulo: Edgard Blücher, 2001.

[11] Okunribido, O.O., Shimbles, S.J., Magnusson, M., Pope, M. City bus driving and low back pain: A study of the exposures to posture demands, manual materials handling and wholebody vibration. Applied Ergonomics, 38 (1), pp. 29-38. 2007.

[12] Salmon, P.M., Young, K.L. and Regan, M.A., Distraction 'on the buses': A novel framework of ergonomics methods for identifying sources and effects of bus driver distraction. Applied Ergonomics, 42(4), pp. 602-610. 2011.

[13] Szeto, G.P.Y. and Lam, P., Work-related musculoskeletal disorders in urban bus drivers of Hong Kong. Journal of Occupational Rehabilitation, 17(2), pp. 181-198. 2007.

[14] Troup, J.D.G., Driver's back pain and its prevention. A review of the postural, vibratory and muscular factors, together with the problem of transmitted road-shock. Applied Ergonomics, 9(4), pp. 207-214. 1978.

[15] TSE, J.L.M., Flin, R. and Mearns, K., Bus driver well-being review: 50 years of research. Transportation Research Part F: Traffic Psychology and Behaviour, 9(2), pp. 89-114. 2006. 
[16] You, H., Bucciaglia, J., Lowe, B., Gilmore, B.J. and Freivalds,

A., An ergonomic design process for a US transit bus operator workstation. Heavy Vehicle Systems, 4(2-4), pp. 91-107. 1997. 